\title{
Sustainable
}

Engagement?

\section{Reflections on the development of a creative community-university partnership}

\section{Jennifer Shea}

San Francisco State University

Gateways: International Journal of Community Research and Engagement Vol 4 (2011): 136-53

(C) UTSePress and the author

ISSN 1836-3393
The current economic crisis provides an opportunity for urban universities to rethink and reshape their relationships with the communities in which they are located. Creative partnerships among universities, city agencies and community organisations have the potential to leverage the strengths of all three to: (1) identify and articulate community-defined needs and priorities; (2) systematically identify and map community resources; (3) provide students with service learning and field research opportunities; and (4) help neighbourhoods and community organisations weather crises and emerge from them stronger. While urban universities have a long history of working with community organisations and city agencies on discrete projects, often those projects are isolated from one another. When project outcomes, lessons learned and related achievements are stored in disciplinary or community silos, a project's impact may be limited, thus forestalling shared learning. Despite the immediate learning and community outcomes of such projects, the community's collective knowledge base may not be advanced and outcomes may not be sustained.

Recognising the untapped potential of the discrete community-university partnerships (CUPs) in San Francisco, San Francisco's Neighborhood Empowerment Network (NEN) and the Institute for Civic and Community Engagement (ICCE) at San Francisco State University (SF State) have been working to develop a collaborative model that involves other Bay Area institutions of higher education partnering with city agencies, nonprofit organisations, businesses and neighbourhood resident leaders. Called NEN University (NENu), this partnership is seen as the academic hub of the NEN, 'a constantly evolving collaboration of community organizations, city agencies, nonprofit organizations, and academic institutions [whose] goal is to empower neighborhoods to become cleaner, greener, healthier, and more inclusive places to live and work' (NEN ndc). As such, NENu is a unique collaboration which will serve to bring the resources of these universities to bear on community defined issues and needs (Eisman 2010b). 
This is an ambitious project, made at once more ambitious and more pertinent given the impact of the current economic crisis on all of the major players in this partnership - the city, the universities, the nonprofit organisations the other community groups. Moreover, it is a work in progress and, as innovative models often do, entails a good deal of learning by doing - not only for students and faculty, but for all involved in crafting the partnership model.

I first became aware of the nascent concepts of NEN and NENu in 2008, and my first opportunity for active involvement came during 2009 when I directed an independent study that had two students in the field conducting research, the purpose and design of which was developed collaboratively with NEN. The independent study research provided one area of traction (alongside several others) for developing the NENu concept, which was still only a fledgling idea at the time, and later in 2009 my services were retained to help craft the NENu concept paper. While that formal role ended in January 2010, I have remained involved, helping first to design interview protocols and later to analyse interview data for a NENu project, and now supervise several students working in various capacities on NENu projects. I am also a member of a related advisory committee.

This article is a reflective piece that fits within a type of scholarship of engagement (McNall et al. 2009), informed by my experiences and observations in the 'doing' of engaged scholarship as it relates to NENu over the course of the past two years. These reflections should not be taken as a comprehensive history or effectiveness analysis of NENu or any of the processes discussed herein. Rather the aim is to contribute to the conversation about the successes and challenges associated with developing and sustaining creative community-university partnerships by nesting those reflections in the relevant literature.

First, a brief overview of the recent literature on CUPs is provided and three categories of threats to CUP sustainability that can be derived from the literature are then identified. Using that framework, the aim is to contribute to the discussion of how best to build sustainable (in that they have staying power beyond the commitment of a few key individuals) and effective (in terms of building or strengthening communities) CUPs. To that end, after describing NENu, the NENu partnership development process is examined in the context of that framework, identifying past and potential threats to sustainability, as well as factors that have in the past or may in the future address those threats. The article concludes with implications for research and practice.

\section{SUSTAINABLE COMMUNITY-UNIVERSITY PARTNERSHIPS: AN OVERVIEW OF THE LITERATURE}

As the sustainability of CUPs is a focus of this article, before delving into the CUP literature, it is worthwhile exploring the concept of sustainability, so prevalent that it is often referred to 
as a paradigm or doctrine (Swidler \& Watkins 2009). In generic terms, sustainability can be thought of as 'long-term survival at a non-decreasing quality of life' (Rose 2007, p. 386), a definition derived from the ecological and ecological economics literatures. In the context of community development, sustainability is equated with maintaining gains in resource-constrained environments that have often faced historic and structural challenges (settings similar to those where community-university partnership projects take place). In this context, threats to sustainability include staff or leadership turnover, shifts in institutional priorities and a lack of funding (Silka et al. 2008).

From the community development perspective, many argue that sustainability requires a greater integration of projects and people, with the infrastructure to support it (e.g. Beard \& Dasgupta 2006; Grosjean \& Kontoleo 2008; Hemphill et al. 2006; Jones-McCrae 2008). According to Spiro (2009), when conceived as long-term stability, sustainability requires consistent funding support, behaviour changes and the ability to adapt. Others see sustainability as being equated with the acts of building capacities or enhancing participation to improve governance, creating a sense of ownership, and fostering more effective and efficient programs and policies (Mathers, Parry \& Jones 2008; Mirabella, Malcolm \& Berger 2007; Smets \& Salman 2008; Sobek 2008; Suarez-Balcazar et al. 2008). More specifically, community involvement is seen to foster innovation, enhance capacity, create local ownership or buy-in, respond to community-identified priorities and promote stability - all of which contribute to sustainability (González \& Healey 2005; Waldman 2009).

Universities are well-positioned to enhance the sustainability of city-community initiatives because universities can help mitigate asymmetries of power and information between residents and city agencies, thus helping to enhance trust (Kathi \& Cooper 2007). The contemporary call for renewed civic engagement in urban universities dates back to the mid-1990s (see, for example: Benson, Harkavy \& Puckett 2000; Jelier \& Clarke 1999; Ostrander 2004; Perkins 1994). Related to that call is the literature on community-university partnerships, which finds itself at the intersection of at least three bodies of literature - one on partnership and network development, a second on communityengaged scholarship, and a third on civic renewal and communitybuilding (see, for example: D'Agostino 2008; McNall et al. 2009; Plastrik \& Taylor nd; Sirianni \& Friedland 2001; Takahashi \& Smutny 2001; Traynor 2008; Wei-Skillern \& Marciano 2008; White 2009).

Due to limitations of time and space, the focus of this overview is on nine overlapping potential threats to sustainable CUPs that emerge from that literature. As seen in Table 1, those threats can be placed into three overarching categories: (1) asymmetries (of power, information and organisational capacity); (2) inadequacies (of rewards, resources and infrastructure); and 
Table 1:Factors for sustainability and associated threats
(3) divergences (in focus, priorities and norms). Each threat corresponds to one or more sustainability factors. For example, the first row of Table 1 reads as follows: 'an asymmetry in power may manifest itself when universities make one-sided decisions about which communities/groups are worthy of partnership; that asymmetry may threaten sustainability by fostering mistrust or discouraging participation'. It is important to note that while these threats have been parsed out for analytical clarity, in reality they often overlap. For example, inadequate funding levels may exacerbate information and power asymmetries, causing small community groups to distrust university partners. Moreover, power asymmetries often overlap with asymmetries in organisational capacities, which may thwart the accommodation of different expressions of power.

\begin{tabular}{|c|c|c|c|}
\hline $\begin{array}{l}\text { Sustainability } \\
\text { factor }\end{array}$ & $\begin{array}{l}\text { Threat } \\
\text { category }\end{array}$ & $\begin{array}{l}\text { Threat } \\
\text { subcategory }\end{array}$ & $\begin{array}{l}\text { Sample manifestation of } \\
\text { threat }\end{array}$ \\
\hline $\begin{array}{l}\text { Trust } \\
\text { Participation } \\
\text { Commitment }\end{array}$ & \multirow{3}{*}{$\begin{array}{l}\text { Asymmetry } \\
\text { (uneven) }\end{array}$} & Power & $\begin{array}{l}\text { - City agencies make rules } \\
\text { and decisions without } \\
\text { consulting community } \\
\text { - Universities decide which } \\
\text { groups are 'worthy' of } \\
\text { partnership }\end{array}$ \\
\hline $\begin{array}{l}\text { Trust } \\
\text { Participation } \\
\text { Commitment }\end{array}$ & & Information & $\begin{array}{l}\text {-All have 'inside' } \\
\text { information from own } \\
\text { perspective (city politics, } \\
\text { recent research, community } \\
\text { priorities and solutions) }\end{array}$ \\
\hline $\begin{array}{l}\text { Participation } \\
\text { Commitment }\end{array}$ & & $\begin{array}{l}\text { Organisation } \\
\text { Capacity }\end{array}$ & $\begin{array}{l}\text {-Mismatch between large, } \\
\text { slow-moving bureaucracies } \\
\text { and smaller flexible groups }\end{array}$ \\
\hline $\begin{array}{l}\text { Participation } \\
\text { Commitment }\end{array}$ & \multirow{3}{*}{$\begin{array}{l}\text { Inadequacy } \\
\text { (not enough) }\end{array}$} & Rewards & $\begin{array}{l}\text {-Faculty/student time } \\
\text { investment not accounted } \\
\text { for in evaluation process } \\
\text {-Community outcomes not } \\
\text { sustained; city or university } \\
\text { 'walks away' }\end{array}$ \\
\hline Commitment & & Resources & $\begin{array}{l}\text { - Low levels of funding } \\
\text { - Too few personnel } \\
\text { - Insufficient knowledge/ } \\
\text { skills }\end{array}$ \\
\hline $\begin{array}{l}\text { Participation } \\
\text { Commitment } \\
\text { Trust }\end{array}$ & & \multicolumn{2}{|c|}{\begin{tabular}{|l} 
Infrastructure - \\
$\qquad \begin{array}{l}\text { technology not fully } \\
\text { developed } \\
\text { - Systems for sharing } \\
\text { funding, decision-making, } \\
\text { etc. do not exist }\end{array}$
\end{tabular}} \\
\hline
\end{tabular}




\begin{tabular}{|c|c|c|c|}
\hline $\begin{array}{l}\text { Sustainability } \\
\text { factor }\end{array}$ & $\begin{array}{l}\text { Threat } \\
\text { category }\end{array}$ & $\begin{array}{l}\text { Threat } \\
\text { subcategory }\end{array}$ & $\begin{array}{l}\text { Sample manifestation of } \\
\text { threat }\end{array}$ \\
\hline Commitment & \multirow{3}{*}{$\begin{array}{l}\text { Divergence } \\
\text { (difference) }\end{array}$} & Focus & $\begin{array}{l}\text { One party prefers ambiguous } \\
\text { definitions or parameters } \\
\text { while others prefer precise } \\
\text { ones }\end{array}$ \\
\hline $\begin{array}{l}\text { Commitment } \\
\text { Participation } \\
\text { Trust }\end{array}$ & & Priorities & $\begin{array}{l}\text { Partners cannot agree on top } \\
\text { priorities }\end{array}$ \\
\hline Trust & & Norms & $\begin{array}{l}\text { Community empowerment } \\
\text { Efficient/effective resource use } \\
\text { Learning and knowledge }\end{array}$ \\
\hline
\end{tabular}

As Table 1 shows, asymmetries refer to uneven amounts between partners, inadequacies refer to insufficient levels or quantities overall, and divergences refer to different norms or strategies among partners. CUPs may face several sustainability threats at once. For example, studies that focus on the characteristics of partnership development themselves look at inadequacies in infrastructure and power asymmetries, suggesting there are lessons to be learned about managing unequal power relations and impacts on the community that may affect the effectiveness of those partnerships (Baum 2000; McNall et al. 2009; Prins 2005; Shefner\& Cobb 2002). Some of the most recent literature suggests that it may be important to view communityuniversity partnerships as creative, strategic, shared power partnerships - crafted intentionally by drawing on and respecting multiple sources of expertise to develop valued, contextualised and innovative ways of strengthening communities (Boyte 2008; White 2009). Nonetheless, the challenges inherent in crafting a shared vision and a shared power system with different institutional interests that can be exacerbated by power differentials between the community (neighbourhood associations, community-based organisations) and bureaucratic institutions like city agencies and urban universities should not be overlooked (Baum 2000; Boyte 2008; McNall et al. 2009; Prins 2005; Shefner \& Cobb 2002; White 2009). Those challenges are rooted in distinct capacities around communications and planning, which are related to divergent institutional priorities, norms and infrastructure. Moreover, none of these entities are monolithic in terms of their cultures, perceptions or priorities.

Inadequate rewards do not refer to personal or professional gain from participating in CUPs, but to the reality that faculty, residents and staff members of community-based organisations or city agencies need to know that their investments of time, energy and money are worthwhile and will be recognised, valued and supported in the long term. For example, while the literature is rich with reports on effective community-engagement research and teaching scenarios, that literature also recognises that those scenarios are labour-intensive for faculty and often not rewarded 
during the tenure process (D'Agostino 2008; Koliba 2007; Waldner $\&$ Hunter 2008). Less prevalent in the literature, but widely recognised among non-profit and community-based practitioners, are the unmet expectations and associated burdens for organisation staff that sometimes accompany community-service learning projects, especially short-term ones (Stoecker \& Tryon 2009). Similarly, according to McNall et al. (2009), one concern expressed by community groups in ongoing partnerships was uncertainty regarding the sustainability of additional resources the partnership may have brought to service delivery systems, a fear confirmed by the experiences of those whose partnerships had ended.

Moreover, while individual efforts are important and can realise marked successes, 'sustained and systemic success' requires some cooperation from and with institutions (White 2009, p.3), needs to be accompanied by an infrastructure that creates a favourable environment for community-building (Traynor 2008) and must be rooted in a set of trusted reciprocal relationships that extend beyond individuals to institutions or organisations (Chaskin 2001; Reardon 2006). Even when multiple groups are involved in collaborative or networked arrangements, two may play primary roles in the partnership, suggesting that certain offices or departments will emerge as the primary connectors between a given agency and the partnership hub (White 2009). However, in the absence of a supportive community-building infrastructure, individual faculty and their counterparts in community organisations bear a heavy burden, in terms of conducting outreach, developing relationships and designing appropriate and effective projects (Stoecker \& Tryon 2009; Waldner \& Hunter 2008). In other words, these projects may face the combined threats of inadequate rewards, resources and infrastructure all at once.

Despite these threats, the literature points to several indicators of successful community-university partnerships, including those grounded in a shared vision, governed using shared power and decision-making, funded using shared resources and managed effectively from a partnership perspective (McNall et al. 2009; Stoecker \& Tryon 2009; Suarez-Balcazar et al. 2008). Those indicators overlap in some ways with qualities of effective networks and partnerships, including 'being well organized, with clear operating procedures and mechanisms for ensuring maximum participation between its members; and having adequate resources to fulfill its purposes, particularly in terms of time, finance and human capital' (Selkrig \& Keamy 2009, p. 189; see also Black 2008). At the root of those success indicators are a set of leaders at various levels who act as boundary spanners, able to understand the needs, priorities and norms of partners outside their arena (university, community, city), translate them to peers inside their arena and foster the development of trust (Reardon 2006). Cross-boundary leaders possess skills and abilities that help them successfully manage and develop interpersonal relationships, especially where power is unequal and priorities distinct. Shared 
power leadership is rooted in an explicitly political, contextualised view of leadership that focuses on how individuals and groups work together to solve complex social problems (Crosby \& Bryson 2005; O'Brien \& Shea 2010).

Sometimes trust-building is a long and delicate process, especially where communities hold historically informed, deeprooted scepticism about the motivations and intentions of universities or city agencies - scepticism that needs to be addressed in order to build trusting, reciprocal relationships (Silka et al. 2008). The process of trust-building may require that universities 'accept the limitations of positivist scholarship in order to benefit from reciprocal learning made possible by the local knowledge contributed by their community partners' (Reardon 2006, p. 107) and that cities resist the urge to advance a predetermined agenda. In other words, partners have to work together in a reciprocal fashion to smooth out asymmetries by establishing infrastructures that address power and information asymmetries while also working to address inadequacies in resources, which may further even out asymmetries, for example.

The section that follows describes NENu, its partners and projects, as well as some of the successes and expected benefits of the partnership. After that description, the sustainability factors and threats framework laid out in Table 1 is used to identify real challenges that surfaced (some of which are ongoing) while defining and refining a shared vision for the NENu partnership and the infrastructure needed to support it. While many of these observations support the existing literature, this analysis contributes by paying particular attention to this unique partnership's structure and the underlying assumptions that seem to have minimised the impacts of those threats.

\section{NENU: A UNIQUE TRILATERAL PARTNERSHIP}

Born out of a series of ongoing conversations and joint activities carried out by Daniel Homsey, Director of the Neighborhood Empowerment Network, San Francisco City Administrator's Office, and Dr Gerald Eisman, Director of ICCE, NENu's evolution has been organic and truly collaborative in nature. Their early conversations were neither a response to a funding opportunity, nor mandated from 'the top'. Rather, both Homsey and Eisman have shared a commitment, personal and professional, to strengthening San Francisco's communities. They have been inspired and informed by the research coming out of the postKatrina recovery, much of which emphasises the importance of building social capital to foster community resiliency (Colten, Kates \& Laska 2008; Morrow 2008), where resiliency refers to 'the ability to adapt to changing conditions and prepare for, withstand, and rapidly recover from disruption' (White House 2010, p. 18).

The NENu partnership model is rooted in a paradigm that values collaboration and recognises that all communities have assets they can build upon to identify and address their collective priorities. More than a set of normative beliefs or assumptions, 
the paradigm reflects current work in the areas of community resilience (Colten, Kates \& Laska 2008; Morrow 2008). As such, NENu works to leverage resources and create synergies to identify and address community priorities in ways that cross institutional and sectoral boundaries. NENu has been described as a hub - a vehicle that facilitates connections among academic institutions, city agencies and other neighbourhood stakeholders:

NEN University (NENu) combines the skills and talents of academic institutions, city agencies, and other neighborhood stakeholders to improve local communities. Through NENu, students earn class credit for projects, such as community asset mapping and leadership training, that make communities more resilient and better places to live (NENu nda).

Driving this view of NENu are intentions to tactically deploy collective assets and collaboratively implement projects; it is what Reardon (2006, p. 97) would call an empowerment/capacitybuilding partnership because it seeks to generate and disseminate practical knowledge in order to enhance community capacity so that partners will be better prepared to identify and address local priorities. Community capacity may be mobilised intentionally or operate through informal interactions; it includes the human capital, organisational resources and social capital that exist and can be leveraged within a community to identify and address collective priorities meant to maintain or enhance the wellbeing of that community (Chaskin 2006, p. 295).

A project must meet four criteria in order to be considered a NENu project or initiative (not all work done by university faculty and students with or in the community fits). First, NENu is unique in that its projects must be implemented collaboratively by all three categories of stakeholders:(1) an academic institution which is a NENu partner, (2) a city/county agency, and (3) a stakeholder from outside the academic and governmental spheres. Second, NENu projects are meant to build on existing assets to further community goals that work toward developing resilient neighbourhoods, where resilient neighbourhoods have the capacities and associational networks that will help them collectively 'bounce back' after a major natural or man-made disaster. The third criterion is meant to facilitate coordination among various NENu projects and partners - it requires NENu initiatives to be publicly described as such. Finally, the findings from NENu projects must be shared with other NENu members, and the community at large. These criteria directly address some of the sustainability threats identified in Table 1.

Figure 1 depicts the relationships among NEN, NENu, the academic institution partners, and the projects and initiatives that fall under $\mathrm{NENu}$. 


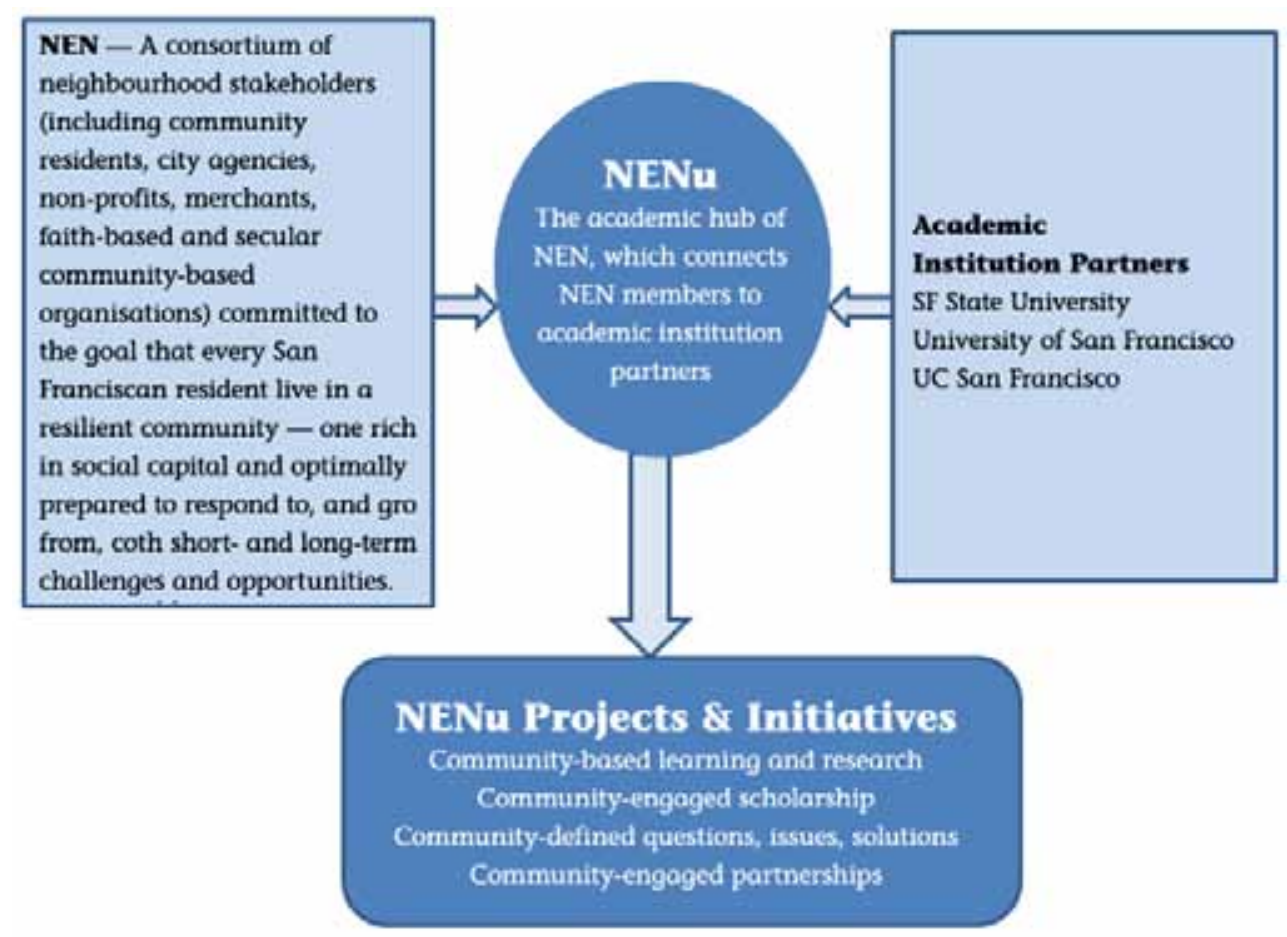

The benefits of the partnership, as identified in the most recent version of the concept paper (28 January 2010), are as follows:

-increases the visibility of the contributions that academic institutions make to San Francisco and its neighbourhoods

-connects the work of service-learning teams to stakeholder-led strategic initiatives

-links community-engaged research projects and products to stakeholders who control assets that can be deployed to support stakeholder-identified outcomes

-increases the perceived value of academic research to community stakeholders

-makes available a suite of applied research that can be shared throughout the city and beyond

-facilitates the development of long-term relationships between academia, the city and the community that increases social capital, which in turn can be leveraged in the recovery from a major earthquake.

These benefits are seen as being achieved over a continuum of time - some immediately, some over a slightly longer time- and, ultimately, in the long term will create sustainable relationships among NEN members and academic institution partners which will contribute to making San Francisco's neighbourhoods more resilient (e.g. safer, cleaner, stronger, more inclusive).

Current academic institution partners include SF State, the University of San Francisco (USF) and the University of California San Francisco (UCSF). Other area academic institutions, including the Presidio Graduate School, Art Institute of California San Francisco and California College of the Arts, have also been approached and are considering engaging in the partnership (at 
the time of writing there are no membership dues or other barriers to joining). In addition, there are plans to reach out to other key institutions like City College of San Francisco.

NENu projects are Engaged Learning Zones (ELZ), multi-phase processes that combine community, university and government resources in a long-term effort to support bottom-up capacitybuilding efforts that address community needs (Eisman 2010a). Several are currently underway, including one in the OuterMission-Ingleside (OMI) neighbourhoods that brings together ' $\mathrm{a}$ wide variety of neighborhood stakeholders to identify and prioritize common challenges, set goals, mobilize available resources, and implement strategies for change ... [to] create a network of agencies and individuals who can bring about positive change for local communities' (ICCE 2010), and the LGBTQ and Polk Corridor (Polk) Resiliency Projects, which work to support and strengthen these communities in their efforts to identify and address existing and emerging challenges (NEN ndb).

NENu partners are already learning - and sharing their learning - from these projects. For example, the OMI and Polk ELZ projects were undertaken by different partners and organised in different ways. The OMI project used a bottom-up approach to identify and build relationships with community stakeholders, and was designed as a multi-phase, multi-year project (Phase I lasted one year). The Polk ELZ relied on an existing community leadership team and expected to skip the long Phase I process. In the end, the Polk ELZ did not take off quickly; it turned out the long Phase I was necessary. As a result, the OMI ELZ model will be used by various NENu partners in other neighbourhoods.

These projects are funded in various ways, often through the community-service learning offices at the academic institution partners, which may have grant funding to support this work. For example, ICCE was recently awarded a sub-grant that it used to support NENu projects. That sub-grant came from the California Campus Compact's grants program that was funded by the Corporation for National and Community Service's (CNCS) Learn and Serve America program, thus bringing federal funding to support neighbourhood work that otherwise would have been invisible to federal funders.

\section{REFLECTIONS ON THE NENU PARTNERSHIP AND ITS SUSTAINABILITY}

The framework of threats to sustainability identified in Table 1 has been used to inform my reflections, which focus on the threats to sustainability encountered during the processes of refining and articulating NENu, how it functions and what it does. These processes include refining the mission, vision and values statements, sketching the basic partnership roles and governance structures, and identifying basic goals and objectives for NENu. 


\section{Concurrent Threat 1: Asymmetry of Power and Inadequacy of Infrastructure}

As conversations meant to foster a shared vision of NENu progressed, it became clear that the city did not want to be perceived as the driving force behind NENu projects. Yet NEN was both closely tied to the city governmental apparatus and in many ways the core of NENu. While NEN was an essential element of NENu, there were good reasons not to put NEN at the centre of the partnership. Among those reasons was the need to convey to sceptical community partners that NENu was not merely a strategic city initiative meant to placate or co-opt certain neighbourhoods or groups. Another important reason was that the concept of NENu was meaningless without the participation of academic institutions, and those academic institutions wanted to be depicted as essential partners. Thus, it was agreed that both NEN and the academic institutions would make essential contributions to the core concept, NENu (refer to Figure 1 for an illustration of those relationships).

While this may seem like an obvious resolution in hindsight, at the time the discussion was muddied because it seemed that NEN played a key convening role in bringing together both neighbourhood groups and academic institutions. In retrospect it appears that the difficulties were due to an underlying sustainability threat caused by inadequacies in the decisionmaking infrastructure and asymmetries in power that no one wanted to (or could) address, as they related to asking what would happen to NENu if one partner disengaged. On the one hand, a potential strength of the partnership was the multiplicity of actors and possible nodes through which institutions and organisations could link to the partnership. On the other hand, concerns were raised that the city, in particular, might at some point disengage wholesale and walk away (that seems unlikely now, given the success of the partnership to date). These concerns suggest that some partners may have been wavering in their commitment to the partnership.

Also falling under power and information asymmetries was a distinct set of challenges related to the use of specific phrases and their connotations. Sensitivities were voiced from all sides, with some terms (e.g. leveraging resources or community problems) being associated with objectifying communities while others were seen as overly sentimental. Other seemingly innocuous terms were seen as exclusive. For example, early on, the term 'neighborhood stakeholders' was meant to refer to those in NENu that were not affiliated with a city agency or an academic institution. As it turned out, at least some of the academic institutions saw themselves as neighbourhood stakeholders, too, as did some municipal entities. It was then agreed that all parties to NENu ought to be considered neighbourhood stakeholders and the quest to find a term to refer to the myriad neighbourhood-based community groups, including houses of worship and businesses, was abandoned. 


\section{Concurrent Threat 2: Asymmetry in Capacity and Inadequacy of Infrastructure}

An ongoing set of challenges revolve around inadequate communications infrastructures and asymmetrical organisational capacities, which may threaten NENu's ability to get buy-in from a wide range of neighbourhood groups and, more importantly, help them to understand and work with university systems. While there is widespread buy-in of the concept of NENu at the institutional level (e.g. city agencies like the Department of Emergency Management and university administrations), more has to be done to ensure that it resonates with community leaders. The differences in buy-in are a result, in part, of the mismatch between the capacities of fast-moving, often informally organised neighbourhood groups that respond to events as they happen and the relatively slow-moving university bureaucracies that are constrained by the academic calendar (e.g. semester system) and course objectives. Three of the academic institution partners (SF State, USF and UCSF) have recently joined forces to take concrete action to address this mismatch, by creating a city-wide database of service learning projects - a major undertaking to which each institution has contributed $\$ 10000$ (G Eisman, personal communication, 9 October 2010).

\section{Concurrent Threat 3: Divergence, Inadequacies and Asymmetries}

From the outset, the group struggled with trying to distinguish the lines between NEN and NENu, including which agencies were members of which group and how formal that membership would be. As time progressed, it became evident that those struggles would manifest themselves again as we worked to illustrate the relationships between these various groups (Figure 1 was the fifth diagram attempt, and is by far the simplest). At the most basic level was difficulty in describing the role of NENu - should it be thought of as a vehicle, an action-centred partnership, a hub of coordination, or some combination of these? In the end, the group came to agree that creating a formal governance structure was premature, which may make it difficult for NENu to survive leadership turnover or a shift in partner roles.

There are a number of possible explanations for these difficulties, though my sense is that this threat represents a trifecta of sorts, where the partners experience a slight divergence in priorities that is exacerbated by power and information asymmetries and inadequate resource levels. But even this trifecta of threats does not seem to have hampered the partnership's development. In fact, recently joint funding proposals have been submitted, including an application for a Fund for the Improvement of Post-secondary Education (FIPSE) grant, with the UCSF taking the lead on writing the proposal. Even in the absence of a formal governance structure, joint funding awards will likely bode well for sustainability. 
Divergences in foci proved to be one of the more contentious points, likely rooted in different motivations and priorities related to NENu. The group was confronted with an ongoing struggle about whether NENu projects ought to be rooted in neighbourhoods (conceived as geographically bound communities) or in communities more broadly. From the city's perspective, restricting NENu projects only to communities with geographic boundaries might alienate some constituencies and thwart city-wide efforts to strengthen communities overall. At the same time, some university representatives were energised by the neighbourhood focus. In the end, it was agreed that NENu projects could cross neighbourhood boundaries, so long as some identifiable community was involved, but that some of the terminology would still focus attention at the neighbourhood level (e.g. neighbourhood stakeholders).

In another instance of divergence, differing institutional priorities and norms revealed themselves. For example, university representatives were concerned that faculty with long histories of community engagement should retain their independence and the integrity of their work, particularly work that may be critical of city policies, agencies and representatives of those agencies. At the same time, city agencies could not be seen as supporting initiatives that criticised or challenged city policies. In short, all of the partners had multiple audiences to whom they were accountable and whose concerns must be weighed. Once these concerns were voiced and understood by all parties, the value NENu added, as compared with traditional partnerships, was illuminated and resulted in the requirement that all three sets of stakeholders needed to buy into a project before it could be considered part of NENu.

\section{Partnership Characteristics Fostering Sustainability}

Each of the specific threats identified above could have threatened trust and participation, key factors in sustainable partnership development. However, the partners worked through these differences, which enabled them to articulate a shared vision for NENu. One factor that facilitated the process was that many of the people at the table had already established good working relationships and enjoyed high levels of interpersonal trust that enabled the group to work through areas of disagreement or divergence. Nonetheless, at the same time, new voices were sometimes brought into the conversation about how best to articulate the vision of $\mathrm{NENu}$, which at times meant that the group had to revisit past discussions to build trust with newcomers and achieve consensus. Despite these challenges, it took the group less than six months to come to consensus, represented by the description of NENu provided on pages $142-45$. It seems that trust, combined with a commitment to the shared vision and the principles of collaborative leadership and broad-based participation, were the essential elements in this outcome.

Another example of the strength of the partnership comes from the resolution of a recent conflict, resulting from a series of 
miscommunications, which resulted in what the city thought was a clear commitment of resources by an academic institution partner to work with a specific neighbourhood, following the ELZ model. On the other hand, the academic institution partner felt that the city had not clearly identified a project or neighbourhood to which to commit those very resources. Further complicating the matter were the expectations of the neighbourhood groups who were anticipating being part of a new ELZ, and the potential negative implications for the city if those expectations were not met. After a series of separate conversations, all parties came to understand that there was no ill will, rather miscommunication was primarily to blame, and the issue was favourably resolved. As a result, another academic institution partner began sharing its internal documents on ELZs with the others to help them understand more clearly how the model works. In addition, the academic institution partners worked together to shift the ways in which their resources were being deployed in two neighbourhoods to ensure that those resources were being used where they would do the most good, while also meeting the goals and expectations of each academic institution partner and ensuring that the neighbourhoods' expectations were met. These actions suggest a commitment to reciprocity and shared learning.

The resolution was possible because NENu is flexible and agile enough to adjust rather quickly (making it compatible with how neighbourhood groups work) and because the actors involved have trust-based relationships that allow them to understand one another's need and accommodate change as needed. While low levels of infrastructure are often seen as a threat to sustainability, it may be that the loose configuration of the partnership will allow it to grow, adapt and become sustainable in a way that a more structured form would prevent - only time will tell.

In short, it appears that the NENu partnership has many characteristics likely to contribute to its sustained effectiveness - reciprocal relationships rooted in trust, shared power, broadbased participation and learning. At the same time, there are other issues related to a long-term funding strategy, handling leadership and transition plans and ensuring a long-term institutional commitment that may prove more challenging for its long-term sustainability. While current efforts to lead and communicate across boundaries are essential to the immediate success of the partnership in order to sustain it, an infrastructure that can support and survive the inevitable leadership transitions a partnership like this will endure is crucial.

\section{Final Thoughts: Implications for Research and Practice}

As Dr Eisman recently remarked (personal communication, 17 September 2010), the real goal of this work is to help communities build their capacity to be at the centre of NENu initiatives. The innovation of NENu is that it convenes multiple academic institutions in a trilateral partnership with city agencies and community groups. Moreover, a representative from each sector 
(academic, city, community) must be involved in a project in order for it to be called a NENu initiative, which requires high levels of cooperation and coordination. The success of NENu thus far can be attributed to four main characteristics: trust, shared power, broadbased participation, and reciprocal learning. These characteristics directly address some of the weaknesses in CUP models that operate as discrete partnerships and are not able to share learning widely.

In more general terms, the reciprocal value partnerships like these can create is essential to their long-term viability and sustainability, but trust-based relationships take time to build and maintain. Certainly, strong partnership networks can and should be able to sustain leadership transitions at multiple levels but they may not be able to sustain commitment levels that waver with political administrations or individual faculty priorities. Therefore, a crucial component of sustainable community-university partnerships may well be institutional, organisational and community commitments that are rooted in norms and cultures that value and support this type of collaborative work. This requires that all partners engage in reflective, ongoing, reciprocal learning processes.

Still, there is much work to be done, both in working to ensure the long-term sustainability of the NENu partnership as it grows and evolves and in systematically examining the processes it uses to navigate the partnership and handle threats to its sustainability. A formal study of the NENu partnership, especially if explicitly compared to other CUPs, may shed more light on its nuances and lead to the development of new hypotheses to test or practices to explore. As the quest for creating more effective CUPs that can demonstrate long-term, community-focused impacts continues, it seems that the NENu partnership may prove an interesting and worthwhile one to model.

\section{ACKNOWLEDGEMENTS}

I am grateful to Dr Gerald Eisman, Director of the Institute for Civic and Community Engagement at San Francisco State University, and Mr Daniel Homsey, Director of the Neighborhood Empowerment Network, San Francisco City Administrator's Office, for their input and feedback on early drafts of this article, as well as their overall support for my writing it. I also appreciate the helpful comments of the anonymous reviewers of this article.

\section{REFERENCES}

Baum, H 2000, 'Fantasies and realities in university-community partnerships', Journal of Planning Education and Research, vol. 20, no. 2, pp. 234-46.

Black, R 2008, 'New school ties: Networks for success', viewed 27 March 2010, www.eduweb.vic.gov.au/edulibrary/public/publ/research/publ/newschool-ties-report.pdf. 
Beard, V \& Dasgupta, A 2006, 'Collective action and community-driven development in rural and urban Indonesia', Urban Studies, vol. 43, no. 9, pp. 1451-68.

Benson, L, Harkavy, I \& Puckett, J 2000, 'An implementation revolution as a strategy for fulfilling the democratic promise of university-community partnerships: Penn-West Philadelphia as an experiment in progress', Nonprofit and Voluntary Sector Quarterly, vol. 29, no. 1, pp. 24-45.

Boyte, H 2008, The citizen solution: How you can make a difference, Minnesota Historical Society Press, St Paul, MN.

Chaskin, R 2001, 'Building community capacity: A definitional framework and case studies from a comprehensive community initiative', Urban Affairs Review, vol. 36, no. 3, pp. 291-323.

Colten, C, Kates, R \& Laska, S 2008, 'Community resilience: Lessons from New Orleans and Hurricane Katrina', CARRI Research Report 3, Community \& Regional Resilience Institute, viewed 22 February 2011, www.resilientus.org/library/FINAL COLTEN 9-25-08 1223482263.pdf.

Crosby B \& Bryson, J 2005, Leadership for the common good, Jossey-Bass, San Francisco, CA.

D'Agostino, M 2008, 'Fostering a civically engaged society: The university and service learning', Journal of Public Affairs Education, vol. 14, no. 2, pp. 191-204.

Eisman, G 2010a, 'The benefits of Engaged Learning Zones', viewed 3 September 2010, www.empowersf.org/home/2010/9/3/the-benefits-ofengaged-learning-zones.html.

Eisman, G 2010b, 'Community is the classroom', viewed 10 February 2010, www.empowersf.org/nenu-blog/tag/san-francisco-state-university.

González, S \& Healey, P 2005, 'A sociological institutionalist approach to the study of innovation in governance capacity', Urban Studies, vol. 42, no. 11, pp. 2055-69.

Grosjean, P \& Kontoleo, A 2008, 'How sustainable are sustainable development programs? The case of the Sloping Land Conversion Program in China', World Development, vol. 37, no. 1, pp. 268-85.

Hemphill, L, McGreal, S, Berry, J \& Watson, S 2006, 'Leadership, power and multisector urban regeneration partnerships', Urban Studies, vol. 43, no. 1 , pp. $59-80$.

ICCE (Institute for Civic and Community Engagement) 2010, NEN University, viewed 1 October 2010, www.sfsu.edu/ icce/programs/nenu. html.

Jelier, R \& Clarke, R 1999, 'The community as a laboratory of study: Getting out of the ivory tower', Journal of Public Affairs Education, vol. 5, no. 2, pp. 167-80.

Jones-McCrae, S 2008, 'Using sport for development and peace', Monday Developments, vol. 26, no. 8, pp. 22-24.

Kathi, P \& Cooper, T 2007, 'The role of the university as a mediating institution in neighborhood council-city agency collaboration', Journal of Public Affairs Education, vol. 13, no. 2, pp. 365-82.

Koliba, C 2007, 'Engagement, scholarship, and faculty work: Trends and implications for public affairs education', Journal of Public Affairs Education, vol. 13, no. 2, pp. 315-34. 
Mathers, J, Parry, J \& Jones, S 2008, 'Exploring resident (non-) participation in the UK New Deal for Communities Regeneration Programme', Urban Studies, vol. 45, no. 3, pp. 591-606.

McNall, M, Reed, C, Brown, R \& Allen, A 2009, 'Brokering communityuniversity engagement', Innovative Higher Education, vol. 33, no. 5, pp. 317-31.

Mirabella, R, Malcolm, M \& Berger, G 2007, 'Nonprofit and philanthropic studies: International overview of the field in Africa, Canada, Latin America, Asia, the Pacific, and Europe', Nonprofit and Voluntary Sector Quarterly, vol. 36, no. 4, suppl., pp. 110s-35s).

Morrow, B 2008, 'Community resilience: A social justice perspective', CARRI Research Report 3, Community \& Regional Resilience Institute, viewed 22 February 2011, www.resilientus.org/library/FINAL MORROW 9-25-08 1223482348.pdf.

NEN (Neighborhood Empowerment Network) nda, 'NENu (NEN University)', viewed 27 March 2010, www.empowersf.org/nenu/.

NEN (Neighborhood Empowerment Network) ndb, 'Projects', viewed 23 February 2011, www.empowersf.org/projectss/.

NEN (Neighborhood Empowerment Network) ndc, 'Welcome to EmpowerSF.org', viewed 27 March 2010, www.empowersf.org/.

O'Brien, E \& Shea, J 2010, 'Women's leadership within their communities', in K O'Connor (ed.), Gender and women's leadership: A reference handbook, vol. 1, Sage Publications, Thousand Oaks, CA, pp. 41-49.

Ostrander, S 2004, 'Democracy, civic participation, and the university: A comparative study of civic engagement on five campuses', Nonprofit and Voluntary Sector Quarterly, vol. 33, no. 1, pp. 74-93.

Perkins, D 1994, 'Why community service and service-learning? Providing rationale and research', Democracy and Education, vol. 9, no. 1, pp. 11-15.

Plastrik, P \& Taylor, M nd, Network power for philanthropy and nonprofits, Barr Foundation, viewed 27 June 2011, www.barrfoundation. org/news?category $=62$.

Prins, E 2005, 'Framing conflict in a community-university partnership', Journal of Planning Education and Research, vol. 25, no. 1, pp. 57-74.

Reardon, K 2006, 'Promoting reciprocity within community/university development partnerships: Lessons from the field', Planning, Practice \& Research, vol. 21, no. 1, pp. 95-107.

Rose, A 2007, 'Economic resilience to natural and man-made disasters: Multidisciplinary origins and contextual dimensions', Environmental Hazards, vol. 7, no. 4, pp. 383-98.

Selkrig, M \& Keamy, R 2009, 'Beyond borderlanders: Universities extending their role in fostering creative partnerships within communities', International Journal of Learning, vol. 16, no. 3, pp. 185-96.

Shefner, J \& Cobb, D 2002, 'Hierarchy and partnership in New Orleans', Qualitative Sociology, vol. 25, no. 2, pp. 273-97.

Silka, L, Forrant, R, Bond, B, Coffey, P, Toof, R, Toomey, D, Turcotte, D \& West, C 2008, 'Community-university partnerships: Achieving continuity in the face of change', Gateways: International Journal of Community Research and Engagement, vol. 1, pp. 128-49. 
Sirianni, C \& Friedland, L 2001, Civic innovation in America: Community empowerment, public policy, and the movement for civic renewal, University of California Press, Los Angeles, CA.

Smets, P \& Salman, T 2008, 'Countering urban segregation: Theoretical and policy innovations from around the globe', Urban Studies, vol. 45, no. 7, pp. 1307-32.

Sobek, J 2008, 'How cost-effective is capacity building in grassroots organizations?', Administration in Social Work, vol. 32, pp. 49-68.

Spiro, J 2009, Leading change handbook: Concepts and tools, Wallace Foundation, New York.

Stoecker, R \& Tryon, E 2009, The unheard voices: Community organizations and service learning, Temple University Press, Philadelphia, PA.

Suarez-Balcazar, Y, Balcazar, R, Taylor-Ritzler, T \& Iriarte, G 2008, 'Capacity building and empowerment: A panacea and challenge for agency-university engagement', Gateways: International Journal of Community Research and Engagement, vol. 1, pp. 179-96.

Swidler, A \& Watkins, S 2009, “Teach a man to fish": The sustainability doctrine and its social consequences', World Development, vol. 37, no. 7, pp. 1182-96.

Takahashi, L \& Smutny, G 2001, 'Collaboration among small, community-based organizations: Strategies and challenges in turbulent environments', Journal of Planning Education and Research, vol. 21, no. 2, pp. 141-53.

Traynor, B 2008, 'Building community in place: Limitations and promise' [Electronic mailing list distribution], reprinted from S Saegart \& J De Fillipis (eds) 2007, Community development reader, Routledge, New York, viewed 27 March 2010, www.lcworks.org/Building\%20Community\%20 in\%20Place.pdf.

Waldman, M 2009, 'Caught in the conflict: Civilians and the international security strategy in Afghanistan', A briefing paper by eleven NGOs operating in Afghanistan for the NATO Heads of State and Government Summit, Oxfam International, Oxford, UK, viewed 21 October 2009, www.oxfamamerica.org/files/caught-in-the-conflict.pdf.

Waldner, L \& Hunter, D 2008, 'Client-based courses: Variations in service learning', Journal of Public Affairs Education, vol. 14, no. 2, pp. 219-39.

Wei-Skillern, J \& Marciano, S 2008, 'The networked nonprofit', Stanford Social Innovation Review, vol. 6, no. 2, pp. 38-43.

White, B 2009, 'Navigating the power dynamics between institutions and their communities', A Study for the Kettering Foundation, viewed 28 March 2010, www.kettering.org/File\%20Library/PDF/Byron\%20 White\%20Navigating\%20Power\%20Dynamics.pdf.

White House 2010, National Security Strategy, viewed 22 February 2011, www.whitehouse.gov/sites/default/files/rss viewer/national security strategy.pdf. 